\title{
Combination of Two Nonlinear Techniques Applied to a 3-DOF Helicopter
}

\author{
P. Ahmadi, ${ }^{1}$ M. Golestani, ${ }^{1}$ S. Nasrollahi, ${ }^{2}$ and A. R. Vali ${ }^{1}$ \\ ${ }^{1}$ Department of Electrical and Electronic Engineering, Malek Ashtar University of Technology, Tehran, Iran \\ ${ }^{2}$ Department of Aerospace Engineering, Sharif University of Technology, Tehran, Iran
}

Correspondence should be addressed to P. Ahmadi; peyman.ahmadi.1366@gmail.com

Received 23 December 2013; Accepted 6 March 2014; Published 17 April 2014

Academic Editors: S. Aus Der Wiesche, P.-C. Chen, and R. K. Sharma

Copyright (C) 2014 P. Ahmadi et al. This is an open access article distributed under the Creative Commons Attribution License, which permits unrestricted use, distribution, and reproduction in any medium, provided the original work is properly cited.

\begin{abstract}
A combination of two nonlinear control techniques, fractional order sliding mode and feedback linearization control methods, is applied to 3-DOF helicopter model. Increasing of the convergence rate is obtained by using proposed controller without increasing control effort. Because the proposed control law is robust against disturbance, so we only use the upper bound information of disturbance and estimation or measurement of the disturbance is not required. The performance of the proposed control scheme is compared with integer order sliding mode controller and results are justified by the simulation.
\end{abstract}

\section{Introduction}

Helicopters are versatile flight vehicles that can perform aggressive maneuvers because of their unique thrust generation and operation principle. They can perform many missions that are dangerous or impossible for human to perform them. Helicopter is a multi-input multioutput (MIMO) highly nonlinear dynamical system, so most of the existing results to date have been based on the linearization model or through several linearization techniques $[1,2]$. The linearization method provides local stability. In presence of disturbance or uncertainties the linearization can lead state variables of system to instability.

In recent years, many papers have been published about control design of helicopter. The sliding mode approach has been employed for helicopter's altitude regulation at hovering $[3,4]$. H-infinity approach has been also used to design a robust control scheme for helicopter [5, 6]. In [5] a robust $\mathrm{H}$-infinity controller has been presented using augmented plant and the performance and robustness of the proposed controller have been investigated in both time and frequency domain. The proposed controller in [6] is based on $\mathrm{H}$ infinity loop shaping approach and it has been shown that the proposed controller is more efficient than classical controller such as PI and PID controller. A robust linear time-invariant controller based on signal compensation has been presented in [7]. By suitably combining feedforward control actions and high-gain and nested saturation feedback laws, a new control scheme has been presented in [8]. Intelligent methods such as fuzzy [9] and neural network theory [10] have been used to design controller. Furthermore, in [11] a new intelligent control approach based on emotional model of human brain has been presented.

The history of fractional calculus goes back 300 years ago. For many years, it has remained with no applications. Recently, this branch of science has become an attractive discussion among control scholars [12]. Good references on fractional calculus have been presented in $[13,14]$. The sliding mode control (SMC) has been also extended in $[12,15-$ 19]. In [15] a PID controller based on sliding mode strategy is designed for linear fractional order systems. In [17] a single input fractional order model, described by a chain of integrators, is considered for nonlinear systems. In [1618] sliding mode method has been applied to synchronize fractional order nonlinear chaotic systems. In [12, 19] sliding surface has been defined as an expressed manifold with fractional order integral.

In this paper, we propose a combination of two nonlinear control techniques, fractional order (FO) sliding mode and 
feedback linearization control methods. The performance of the proposed control scheme is compared with integer order (IO) sliding mode controller and results are justified by the simulation.

This paper is organized as follows: in Section 2, the integer order SMC and feedback linearization techniques are briefly reviewed, and, in Section 3, some preliminaries and definitions of fractional order calculus are introduced. In Section 4, the 3-DOF helicopter model description is presented. In Section 5, the proposed controller scheme is given, and, in Section 6, the proposed approach is applied to 3-DOF helicopter model and experimental results are provided. Finally, conclusion is addressed in Section 7.

\section{Review of IO SMC and Feedback Linearization}

In this section, definitions of sliding mode and feedback linearization control methods are briefly reviewed for essential preparation of the combination of two nonlinear control techniques, FO SMC and feedback linearization.

2.1. Integer Order Sliding Mode Control. Consider a secondorder nonlinear dynamical system as

$$
\dot{x}_{1}=x_{2} \quad \dot{x}_{2}=f(x)+g(x) u,
$$

where $x=\left[\begin{array}{ll}x_{1} & x_{2}\end{array}\right]^{T}$ is the system state vector, $f(x)$ and $g(x)$ are nonlinear functions of $x$, and $u \neq 0$ is the scalar input. Sliding mode control approach consists of two parts, correctivecontrol law $\left(u_{c}\right)$ that compensates the deviations from the sliding surface to reach the sliding surfaceand equivalent control law $\left(u_{\mathrm{eq}}\right)$ that makes the derivative of the sliding surface equal zero to stay on the sliding surface. This control law is represented as

$$
u=u_{\mathrm{eq}}+u_{c}
$$

In general, the sliding surface is $S=x_{2}+\beta x_{1}$, where $\beta>0$.

To guarantee the existence of sliding mode, the control law must satisfy the condition

$$
\frac{1}{2} \frac{d}{d t} s^{2}<0
$$

To have a fast convergence, it is sufficient to modify the sliding surface.

2.2. Input-Output Linearization Control. Consider the following nonlinear dynamical system:

$$
\dot{x}=f(x)+g(x) u \quad y=h(x) .
$$

The control method consists of the following steps.

(a) Differentiate $y$ until $u$ appears in one of the equations for the derivatives of $y$. Consider

$$
y^{(r)}=\alpha(x)+\beta(x) u
$$

(b) Choose $u$ to give $y(r)=v$, where $v$ is the synthetic input. Consider

$$
u=\frac{1}{\beta(x)}[-\alpha(x)+v] .
$$

(c) Then the system has the following form:

$$
\frac{Y(s)}{V(s)}=\frac{1}{s^{r}}
$$

Design a linear control law for this $r$-integrator linear system.

(d) Check internal dynamics.

\section{Basic Description of Fractional Calculus}

There exist many definitions of fractional derivative. Two of the most commonly used definitions are the RiemannLiouville (RL) and Caputo (C) definitions [14].

Definition 1 (see [20]). The left RL fractional derivative is described by

$$
{ }_{a}^{\mathrm{RL}} D_{t}^{\alpha} f(t)=\frac{1}{\Gamma(n-\alpha)} \frac{d^{n}}{d t^{n}} \int_{a}^{t} \frac{f(\tau)}{(t-\tau)^{\alpha-n+1}} d \tau,
$$

where $n$ is the first integer which is not less than $\alpha$, that is, $n-1 \leq \alpha<n$ and $\alpha>0$, and $\Gamma(\cdot)$ is the gamma function.

Definition 2 (see [21]). The Laplace transform of the RL definition is described as

$$
\int_{0}^{\infty} e^{-s t} D_{t}^{\alpha} f(t) d t=s^{\alpha} F(s)-\left.\sum_{k=0}^{n-1} s^{k}{ }_{a} D_{t}^{\alpha-k-1} f(t)\right|_{t=0} .
$$

Lemma 3 (see [20]). The following equality is satisfied for all $\alpha>0$ and $n$ is a natural number. Consider

$$
\begin{aligned}
& \frac{d^{n}}{d t^{n}}\left\{{ }^{R L} D^{\alpha} f(t)\right\}={ }^{R L} D^{n+\alpha} f(t), \\
& { }^{C} D^{\alpha}\left\{\frac{d^{n}}{d t^{n}} f(t)\right\}={ }^{C} D^{n+\alpha} f(t) .
\end{aligned}
$$

Lemma 4 (see [21]). Fractional differentiation and fractional integration are linear operations. Consider

$$
{ }_{0} D_{t}^{\alpha}(a f(t)+b g(t))=a_{0} D_{t}^{\alpha} f(t)+b_{0} D_{t}^{\alpha} g(t) .
$$

Lemma 5 (see [20]). The following equality for left $R L$ definition is satisfied for all $\alpha \in(0,1)$ :

$$
{ }^{R L} D^{\alpha}\left\{I^{\alpha} f(t)\right\}=f(t), \quad \alpha \in(0,1) .
$$

However the opposite is not true, since

$$
I^{\alpha}\left\{{ }^{R L} D^{\alpha} f(t)\right\}=f(t)-\frac{f_{1-\alpha}(0)}{\Gamma(\alpha)} t^{\alpha-1},
$$

where $f_{1-\alpha}(0)=\lim _{t \rightarrow 0} I^{1-\alpha} f(t)$. 


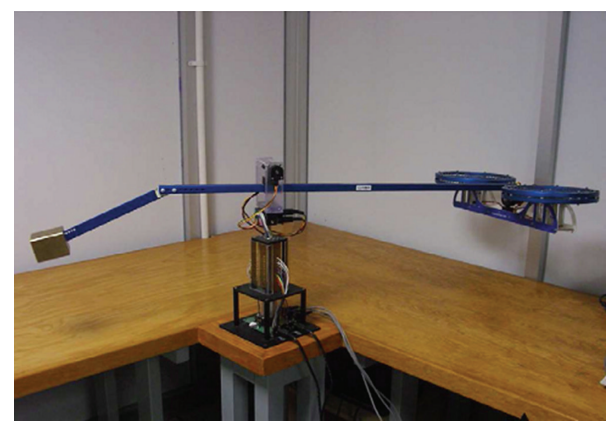

Figure 1: The 3-DOF helicopter system.

\section{System Description}

In this work, a 3-DOF helicopter model is considered (see Figure 1).

The following notations are used to describe the 3-DOF helicopter system dynamics:

$\theta$ : is angular position of the pitch axis, rad;

$\varphi$ : is angular position of the roll axis, rad;

$\psi$ : is angular position of the yaw axis, rad;

$J_{\theta}$ : is moment of inertia of the system around the pitch axis, $\mathrm{kg} \mathrm{m}^{2}$;

$J_{\varphi}$ : is moment of inertia of the helicopter body about the roll axis, $\mathrm{kg} \mathrm{m}^{2}$;

$J_{\psi}$ : is moment of inertia of the helicopter body about the yaw axis, $\mathrm{kg} \mathrm{m}^{2}$;

$V_{l}$ : is voltage applied to the left motor, $\mathrm{V}$;

$V_{r}$ : is voltage applied to the right motor, $\mathrm{V}$;

$K_{f}$ : is force constant of the motor combination, $\mathrm{N}$;

$l_{a}$ : is distance between the base and the helicopter body, $\mathrm{m}$;

$l_{h}$ : is distance from the pitch axis to either motor, $\mathrm{m}$;

$T_{g}$ : is effective gravitational torque, $\mathrm{N} \mathrm{m}$;

$K_{p}$ : is constant of proportionality of the gravitational force, $\mathrm{N}$.

The 3-DOF helicopter control system consists of two DC motors at the end of the arm as shown in Figure 1. Figure 2 shows a physical model of the 3-DOF helicopter. The following equations (see Figure 2) describe the 3-DOF helicopter dynamics:

$$
\begin{gathered}
\ddot{\psi}=-\frac{K_{p} l_{a}}{J_{\psi}} \sin (\varphi), \\
\ddot{\theta}=-\frac{T_{g}}{J_{\theta}}+\frac{K_{f} l_{a}}{J_{\theta}}\left(V_{l}+V_{r}+\xi_{\varphi}\right), \\
\ddot{\varphi}=\frac{K_{f} l_{h}}{J_{\varphi}}\left(V_{l}-V_{r}\right), \\
y=[\psi \theta \varphi]^{T} .
\end{gathered}
$$

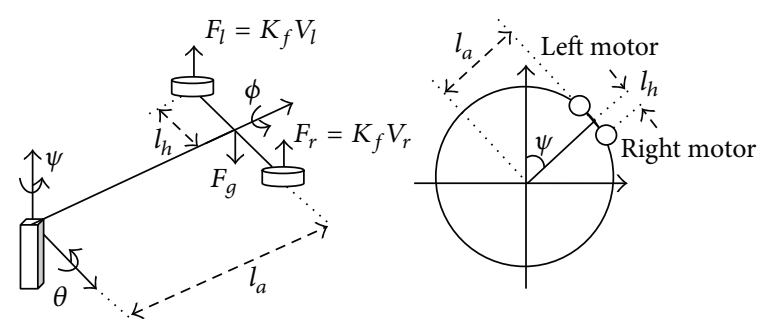

FIgURE 2: Schematic diagram of the 3-DOF helicopter.

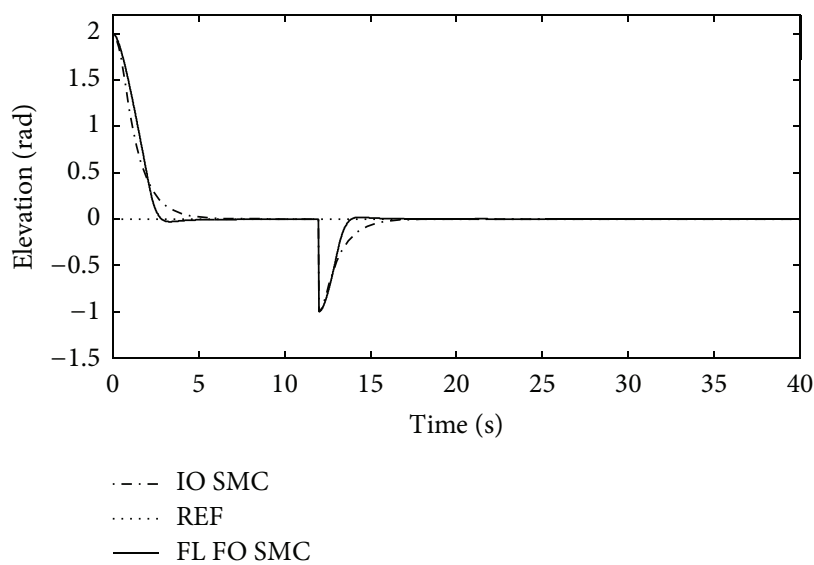

FIgURE 3: Stability curve of elevation.

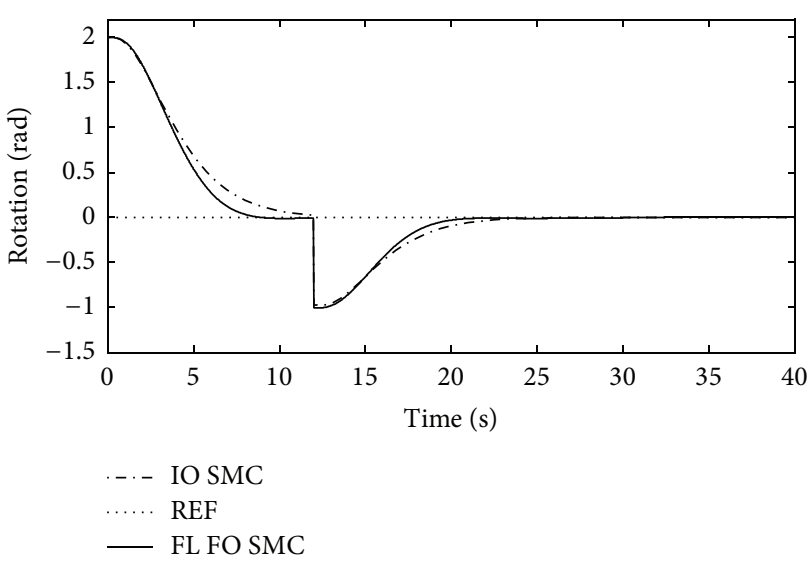

FIGURE 4: Stability curve of rotation.

Let define $u_{1}=V_{l}+V_{r}$ and $u_{2}=V_{l}-V_{r}$; for the sake of

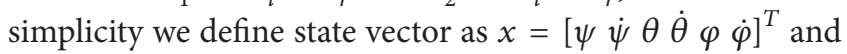
the model (14)-(16) can be rewritten as

$$
\begin{gathered}
\dot{x}_{1}=x_{2} \quad \dot{x}_{2}=-\frac{T_{g}}{J_{\theta}}+\frac{K_{f} l_{a}}{J_{\theta}}\left(u_{1}+\xi_{\varphi}\right), \\
\dot{x}_{3}=x_{4} \quad \dot{x}_{4}=-\frac{K_{p} l_{a}}{J_{\psi}} \sin \left(x_{5}\right), \\
\dot{x}_{5}=x_{6} \quad \dot{x}_{6}=\frac{K_{f} l_{h}}{J_{\varphi}} u_{2} .
\end{gathered}
$$




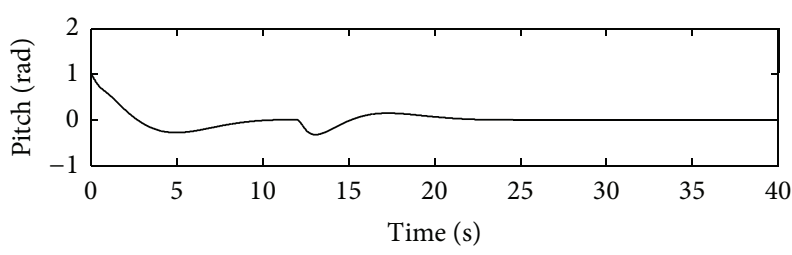

- FL FO SMC

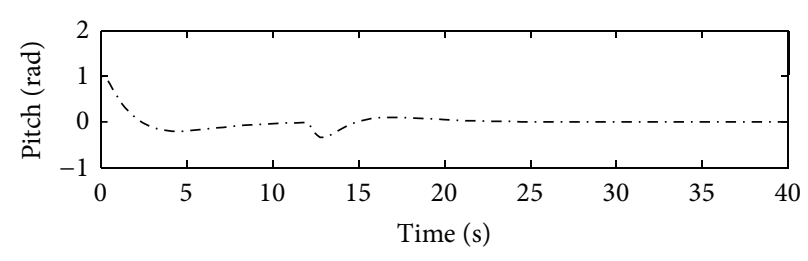

... IO SMC

(a)

(b)

FIGURE 5: Stability curve of pitch.

Furthermore, let vectors $X_{1}$ and $X_{2}$ represent the partitions of the state vector, respectively. Thus, $x=\left[X_{1}{ }^{T}, X_{2}{ }^{T}\right]^{T}$, where $X_{1} \in R^{2}$ and $X_{2} \in R^{4}$. Hence, $\dot{X}_{1}$-subsystem and $\dot{X}_{2^{-}}$ subsystem are presented as follows:

$$
\begin{gathered}
\dot{X}_{1} \text {-subsystem: }\left\{\begin{array}{l}
\dot{x}_{1}=x_{2} \\
\dot{x}_{2}=-\frac{T_{g}}{J_{\theta}}+\frac{K_{f} l_{a}}{J_{\theta}}\left(u_{1}+\xi_{\varphi}\right),
\end{array}\right. \\
\dot{X}_{2} \text {-subsystem: }\left\{\begin{array}{l}
\dot{x}_{3}=x_{4} \\
\dot{x}_{4}=-\frac{K_{p} l_{a}}{J_{\psi}} \sin \left(x_{5}\right) \\
\dot{x}_{5}=x_{6} \\
\dot{x}_{6}=\frac{K_{f} l_{h}}{J_{\varphi}} u_{2} .
\end{array}\right.
\end{gathered}
$$

\section{Design of Controller}

It will be seen that $\dot{X}_{1}$-subsystem and $\dot{X}_{2}$-subsystem have no coupling. We know feedback linearization scheme is suitable approach for multivariable systems but is not robust inherently. Sliding mode control is well known as a robust nonlinear control scheme by disturbance rejection capability. Because feedback linearization is a simple method and the FO SMC method is robust against disturbance, so we combine these two approaches. Firstly, feedback linearization method is applied; secondly, FO SMC method is used. Our control approach is formed in two steps. In the first step, a fractional order sliding mode controller for $\dot{X}_{1}$-subsystem is designed; then, since the $\dot{X}_{2}$-subsystem is multivariable and nonlinear, feedback linearization control is applied. For $\dot{X}_{2}$-subsystem, controller must be robust against disturbance. After linearization, a fractional order sliding mode controller is proposed for linearized subsystem. This helicopter model is an underactuated system by three outputs and two inputs, so we can control two outputs and third output only is kept limited.

Consider $\dot{X}_{1}$-subsystem as

$$
\ddot{x}_{1}=f+g u_{1} \text {. }
$$

Let define sliding surface as $S_{1}={ }^{\mathrm{RL}} D^{\alpha} \ddot{e}_{1}+\lambda_{1} e_{1}$ and the error signal is defined as $e_{1}=x_{1 d}-x_{1}$. Also, disturbance is imposed to roll and yaw channel.

The fractional order sliding mode control input signal can be defined as follows for subsystem (20), [12]:

$$
\begin{aligned}
u_{1}(t)=g^{-1}\left[\ddot{x}_{d}(t)-f+{ }^{\mathrm{RL}} D^{-1-\alpha}\left(\lambda_{1} \dot{e}_{1}\right)\right. \\
\left.+{ }^{\mathrm{RL}} D^{-1-\alpha}\left(k_{1} S_{1}+k_{1} \operatorname{sign}\left(S_{1}\right)\right)\right],
\end{aligned}
$$

where $k_{1}$ and $\lambda_{1}$ are positive constants.

In [12], it has been shown that this control input signal guarantees the stability of the closed-loop $\dot{X}_{1}$-subsystem and the tracking error converges to zero in finite time. Then, in order to control $\dot{X}_{2}$-subsystem, at first we use input-output feedback linearization method. Feedback linearization control law is defined as

$$
u_{2}(t)=\left(-\frac{K_{p} l_{a}}{J_{\psi}} \cos \left(x_{5}\right)\right)^{-1}\left[V-\frac{K_{p} l_{a}}{J_{\psi}} x_{6} \sin \left(x_{5}\right)\right] .
$$

$V$ is new control law that will be designed for linearized system. So we want to obtain overall control law that it has robustness behavior and good performance. We use fractional order control instead of integer order to design control input $V$.

The sliding mode control law, $V$, is designed as follows:

$$
\begin{aligned}
V= & x_{3 d}^{(4)}-\lambda_{2}^{3{ }^{\mathrm{RL}}} D^{\beta} \dot{e}_{2}-3 \lambda_{2}^{2}{ }^{\mathrm{RL}} D^{\beta} \ddot{e}_{2} \\
& -3 \lambda_{2}{ }^{\mathrm{RL}} D^{\beta} e_{2}^{(3)}-k_{2} \operatorname{Sgn}\left(S_{2}\right) .
\end{aligned}
$$

Let the sliding surface equation be proposed as follows:

$$
S_{2}=e_{2}^{(3)}+\lambda_{2}^{3}{ }^{\mathrm{RL}} D^{\beta} e_{2}+3 \lambda_{2}^{2}{ }^{\mathrm{RL}} D^{\beta} \dot{e}_{2}+3 \lambda_{2}{ }^{\mathrm{RL}} D^{\beta} \ddot{e}_{2} .
$$

The error signal is defined as $e_{2}=x_{3}-x_{3 d}$ and the Lyapunov function is to be defined as

$$
\widetilde{V}=\frac{1}{2} S_{2}^{2}
$$




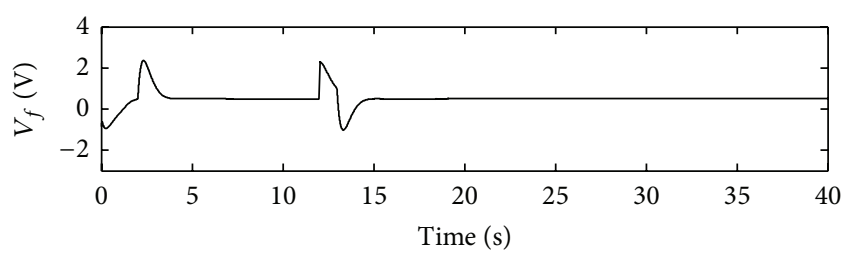

- $V_{f}$ control effort-FL FO SMC

(a)

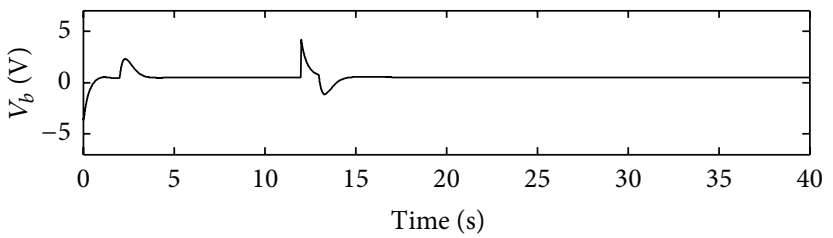

$-V_{b}$ control effort-FL FO SMC

(b)

FIGURE 6: Force control inputs of proposed controller (stability).

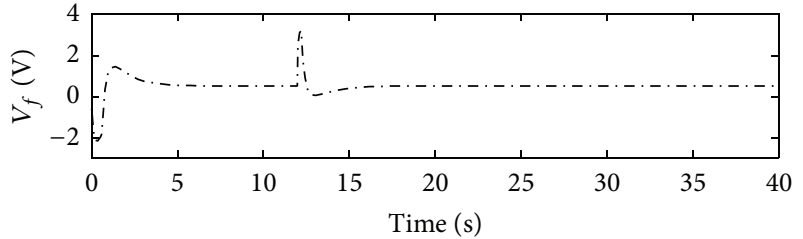

... $V_{f}$ control effort-IO SMC

(a)

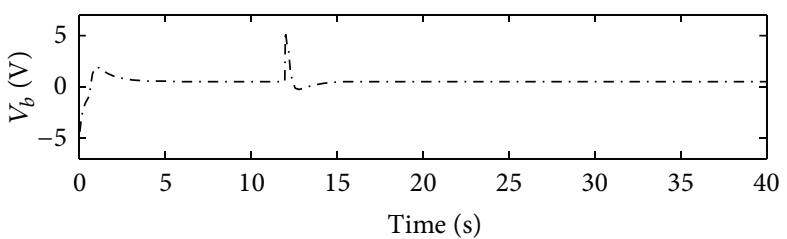

-.. $V_{b}$ control effort-IO SMC

(b)

FIGURE 7: Force control inputs of IO SMC (stability).

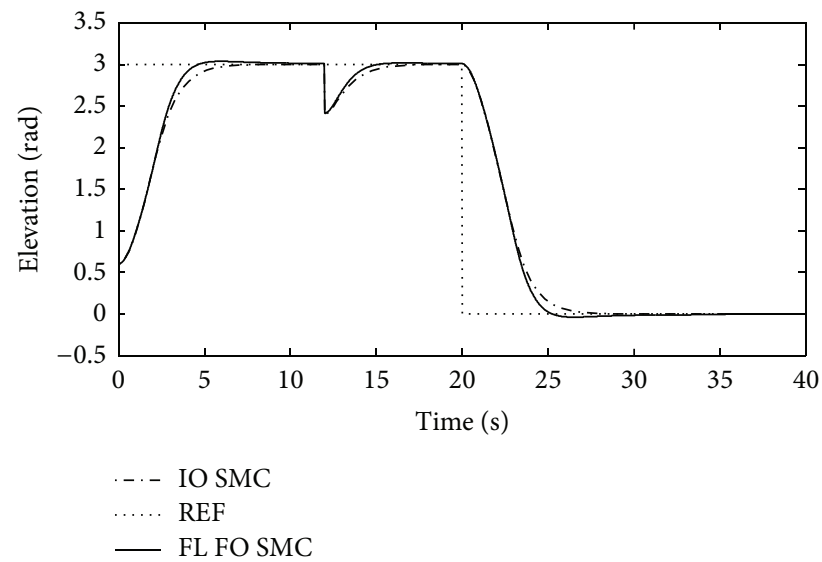

FIGURE 8: Tracking curve of elevation.

Consider the sufficient condition for the existence finite time convergence is

$$
\frac{1}{2} \frac{d}{d t} S_{2}^{2}(t) \leq-k_{2}\left|S_{2}(t)\right|
$$

where $k_{2}$ is a positive constant. Taking time derivative of both sides of (25), according to Lemmas 3 and 5, then we have

$$
\begin{aligned}
\dot{\widetilde{V}}=S_{2} \dot{S}_{2}=S_{2}( & e_{2}^{(4)}+\lambda_{2}^{{ }^{3}{ }^{R L}} D^{\beta+1} e_{2} \\
& \left.+3 \lambda_{2}^{2}{ }^{R L} D^{\beta+1} \dot{e}_{2}+3 \lambda_{2}{ }^{R L} D^{\beta+1} \ddot{e}_{2}\right)
\end{aligned}
$$

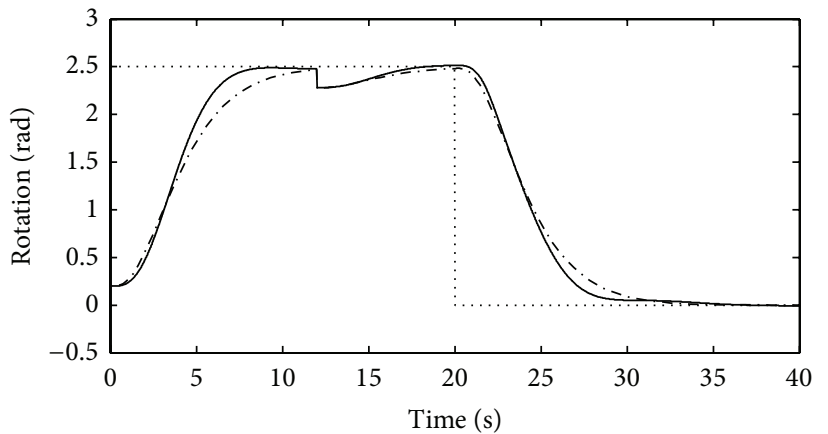

-. IO SMC

..... REF

- FL FO SMC

FIgURE 9: Tracking curve of rotation.

$$
\begin{aligned}
=S_{2}( & V-x_{3 d}^{(4)}+\lambda_{2}^{{ }^{\mathrm{RL}}} D^{\beta+1} e_{2} \\
& \left.+3 \lambda_{2}^{2}{ }^{\mathrm{RL}} D^{\beta+1} \dot{e}_{2}+3 \lambda_{2}{ }^{\mathrm{RL}} D^{\beta+1} \ddot{e}_{2}\right)
\end{aligned}
$$

Replacing (23) into (27) gives

$$
\dot{\vec{V}}=S_{2} \dot{S}_{2}=S_{2}\left(-k_{2} \operatorname{sgn}\left(S_{2}\right)\right) \leq-\left(k_{2}+F\right)\left|S_{2}\right|,
$$

where $F$ is maximum of disturbance. So, total feedback linearization fractional order sliding mode control (FL FO 


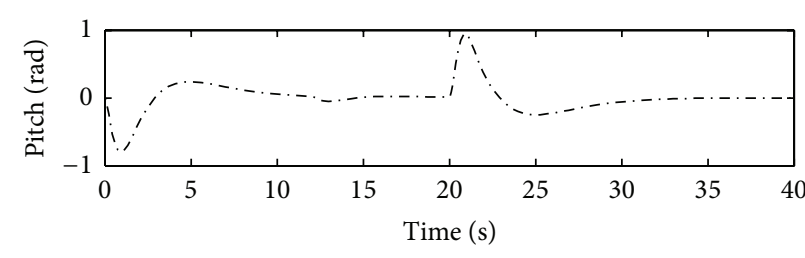

-..- IO SMC

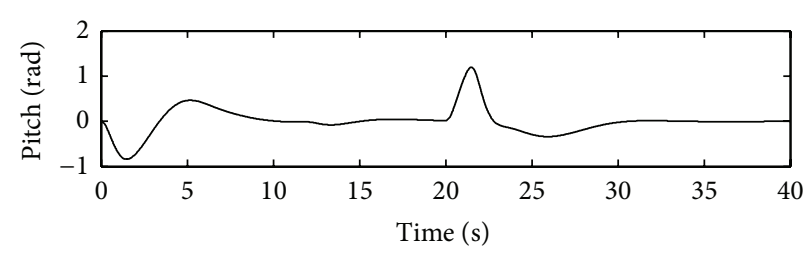

FL FO SMC

(a)

(b)

FIGURE 10: Tracking curve of pitch.

SMC) law is achieved by combination of (22) and (23) that is represented as follows:

$$
\begin{aligned}
u_{2}(t)=\left(-\frac{K_{p} l_{a}}{J_{\psi}} \cos \left(x_{5}\right)\right)^{-1} \\
\times\left[x_{3 d}^{(4)}-\lambda_{2}^{3{ }^{\mathrm{RL}}} D^{\beta} \dot{e}_{2}-3 \lambda_{2}^{2}{ }^{\mathrm{RL}} D^{\beta} \ddot{e}_{2}\right. \\
-3 \lambda_{2}{ }^{\mathrm{RL}} D^{\beta} e_{2}^{(3)}-k_{2} \operatorname{Sgn}\left(S_{2}\right) \\
\left.\quad-\frac{K_{p} l_{a}}{J_{\psi}} x_{6} \sin \left(x_{5}\right)\right] .
\end{aligned}
$$

These two control laws, $u_{1}$ and $u_{2}$, are applied to 3 -DOF helicopter model and simulation results are shown in the next section.

\section{Simulation Results}

To see the performance of the proposed controller, we have simulated the controlled system. The results have been compared with integer order sliding mode controller. The helicopter nominal parameters are shown in Table 1. We choose $\alpha=0.1, \beta=0.15$ in this simulation. Furthermore, a step disturbance is applied in $t=12 \mathrm{sec}$.

To investigate the stability of the closed-loop system, the initial conditions are applied and the reference input is considered to be zero. The time response of the states of the system (18) in the presence of the control laws (21) and (29) is illustrated in Figures 3, 4, and 5. It can be seen that under the proposed controller the output converges to zero and when a disturbance applies the proposed controller is able to nullify the output again. It is clear that the convergence rate in the proposed controller is more than the integer order controller.

The force control inputs are given in Figures 6, and 7. Although the proposed controller is faster than integer order controller in states convergence rate, it requires less control signals energy compared with the integer order SMC controller.

The simulation results of the reference tracking under the disturbance are illustrated in Figures 8, 9, and 10. These figures show that the helicopter can follow the reference trajectory under the proposed control method, and the output response under the proposed control scheme is faster
TABle 1: Parameters' values.

\begin{tabular}{lcc}
\hline Parameter & Value & Unit \\
\hline$J_{\theta}$ & 0.91 & $\left(\mathrm{kgm}^{2}\right)$ \\
$J_{\varphi}$ & 0.0364 & $\left(\mathrm{kgm}^{2}\right)$ \\
$J_{\psi}$ & 0.91 & $\left(\mathrm{kgm}^{2}\right)$ \\
$K_{f}$ & 0.5 & $(\mathrm{~N})$ \\
$K_{p}$ & 0.5 & $(\mathrm{~N})$ \\
$l_{a}$ & 0.66 & $(\mathrm{~m})$ \\
$l_{h}$ & 0.177 & $(\mathrm{~m})$ \\
$T_{g}$ & 0.33 & $(\mathrm{Nm})$ \\
\hline
\end{tabular}

than another one in spite of disturbance. Also the pitch angle remained limited.

The control efforts have been shown in Figures 11 and 12. According to these figures it can be seen that although the proposed controller is faster than integer order controller, it needs less control effort. To implement the controller it is essential that the control effort has an acceptable value.

According to these simulations, it can be seen that the tracking performance of proposed controller is more efficient, with less control effort compared with the integer order sliding mode controller in spite of disturbances.

\section{Conclusion}

In this paper, we presented a combination of two nonlinear control techniques applied to 3-DOF helicopter. Also we considered disturbance in roll and yaw channel. In fact we have used feedback linearization fractional order sliding mode theory to control roll and yaw channel. It is desirable that the outputs track the reference input in less time. In practical application, a high-gain controller may be undesirable. So in this paper a fractional order controller was developed to increase the convergence rate in less control signal energy. To verify the performance of the proposed controller, it was compared with integer order sliding mode theory. The results show that the proposed method also simplifies the design process due to the use of feedback linearization control mechanism for multivariable systems, the sliding mode method advantages, such as robustness is retained. The 


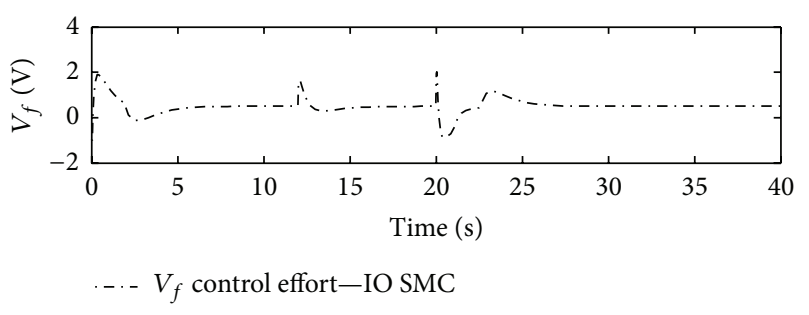

(a)

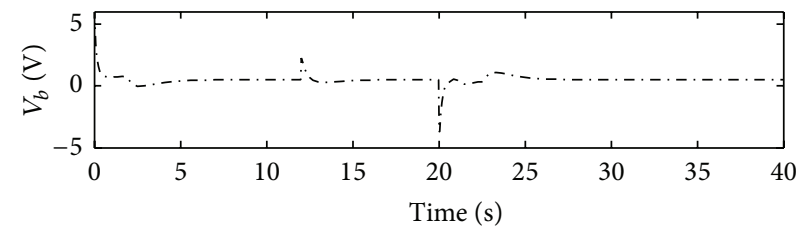

-.. $V_{b}$ control effort-IO SMC

(b)

FIGURE 11: Force control inputs of proposed controller (tracking).

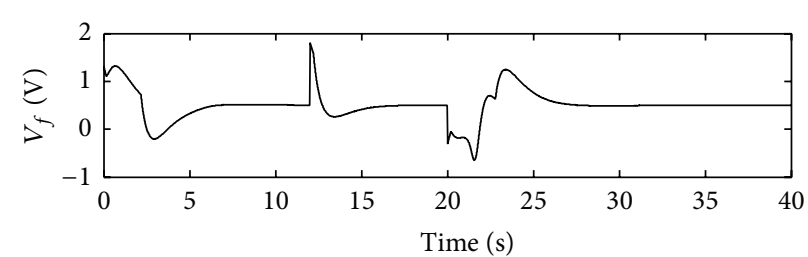

- $V_{f}$ control effort-FL FO SMC

(a)

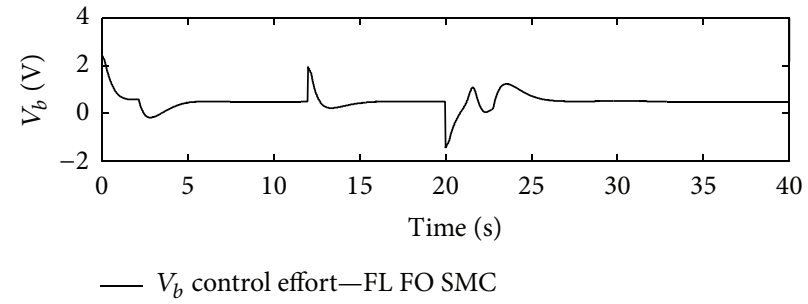

(b)

FIGURE 12: Force control inputs of pitch (tracking).

reason is that after linearization, a fractional order sliding mode controller is designed for linearized subsystem.

\section{Conflict of Interests}

The authors declare that there is no conflict of interests regarding the publication of this paper.

\section{References}

[1] K. H. Kienitz, Q.-H. Wu, and M. Mansour, "Robust stabilization of a helicopter model," in Proceedings of the 29th IEEE Conference on Decision and Control, pp. 2607-2612, December 1990.

[2] W. Garrad and E. Low, "Eigenspace design of helicopter flight control systems," Tech. Rep., Department of Aerospace Engineering and Mechanics, University of Minnesota, 1990.

[3] K. M. Im and W. Ham, "Sliding mode control for helicopter attitude regulation at hovering," Journal of Control, Automation and Systems Engineering, vol. 3, no. 6, pp. 563-568, 1997.

[4] A. Ferreira de Loza, H. Ríos, and A. Rosales, "Robust regulation for a 3-DOF helicopter via sliding-mode observation and identification," Journal of the Franklin Institute, vol. 349, no. 2, pp. 700-718, 2012.

[5] D. Jeong, T. Kang, H. Dharmayanda, and A. Budiyono, " $H$-infinity attitude control system design for a small-scale autonomous helicopter with nonlinear dynamics and uncertainties," Journal of Aerospace Engineering, vol. 25, no. 4, pp. 501518, 2011.

[6] M. Boukhnifer, A. Chaibet, and C. Larouci, " $H$-infinity robust control of 3-DOF helicopter," in Proceedings of the 9th International Multi-Conference on Systems, Signals and Devices (SSD '12), 2012.

[7] Y. Yu and Y. Zhong, "Robust attitude control of a 3DOF helicopter with multi-operation points," Journal of Systems Science and Complexity, vol. 22, no. 2, pp. 207-219, 2009.
[8] L. Marconi and R. Naldi, "Robust full degree-of-freedom tracking control of a helicopter," Automatica, vol. 43, no. 11, pp. 1909-1920, 2007.

[9] H. T. Nguyen and N. R. Prasad, "Development of an intelligent unmanned helicopter," in Fuzzy Modeling and Control: Selected Works of M. Sugeno, pp. 13-43, CRC Press, NewYork, NY, USA, 1999.

[10] A. J. Calise and R. T. Rysdyk, "Nonlinear adaptive flight control using neural networks," IEEE Control Systems Magazine, vol. 18, no. 6, pp. 14-24, 1998.

[11] S. Jafarzadeh, R. Mirheidari, and M. Jahed Motlagh, "Intelligent autopilot control design for a 2-DOF helicopter model," International Journal of Computers, Communications \& Control, vol. 3, pp. 337-342, 2008.

[12] S. Dadras and H. R. Momeni, "Fractional terminal sliding mode control design for a class of dynamical systems with uncertainty," Communications in Nonlinear Science and Numerical Simulation, vol. 17, no. 1, pp. 367-377, 2012.

[13] I. Podlubny, Fractional Differential Equations, Academic Press, New York, NY, USA, 1999.

[14] A. Kilbas, H. Srivastava, and J. Trujillo, Theory and Application of Fractional Differential Equations, North Holland Mathematics Studies, Edited by J. van Mill, Elsevier, 2006.

[15] A. J. Calderón, B. M. Vinagre, and V. Feliu, "Fractional order control strategies for power electronic buck converters," Signal Processing, vol. 86, no. 10, pp. 2803-2819, 2006.

[16] R. El-Khazali, W. Ahmad, and Y. Al-Assaf, "Sliding mode control of generalized fractional chaotic systems," International Journal of Bifurcation and Chaos, vol. 16, no. 10, pp. 3113-3125, 2006.

[17] M. O. Efe and C. A. Kasnakog̃lu, "A fractional adaptation law for sliding mode control," International Journal of Adaptive Control and Signal Processing, vol. 22, no. 10, pp. 968-986, 2008. 
[18] M. S. Tavazoei and M. Haeri, "Synchronization of chaotic fractional-order systems via active sliding mode controller," Physica A, vol. 387, no. 1, pp. 57-70, 2008.

[19] A. Si-Ammour, S. Djennoune, and M. Bettayeb, "A sliding mode control for linear fractional systems with input and state delays," Communications in Nonlinear Science and Numerical Simulation, vol. 14, no. 5, pp. 2310-2318, 2009.

[20] A. Pisano, M. Rapaic, Z. Jelicic, and E. Usai, "Nonlinear fractional PI control of a class of fractional order systems," in IFAC Conference on Advances in PID Control, pp. 637-642, 2012.

[21] C. A. Monje, Y. Q. Chen, B. M. Vinagre, D. Xue, and V. Feliu, Fractional Order Systems and Control: Fundamentals and Applications, Springer, 2010. 

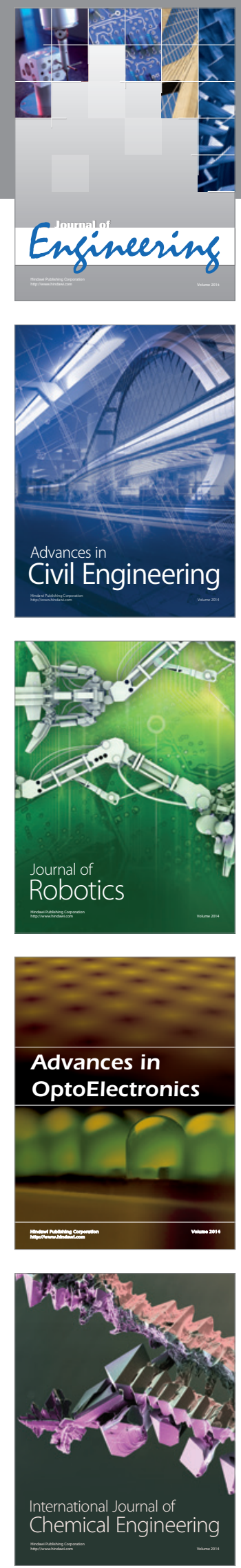

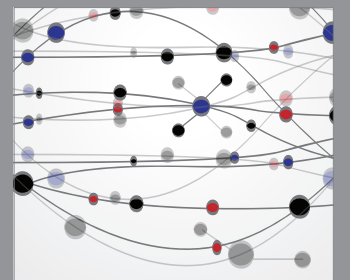

The Scientific World Journal
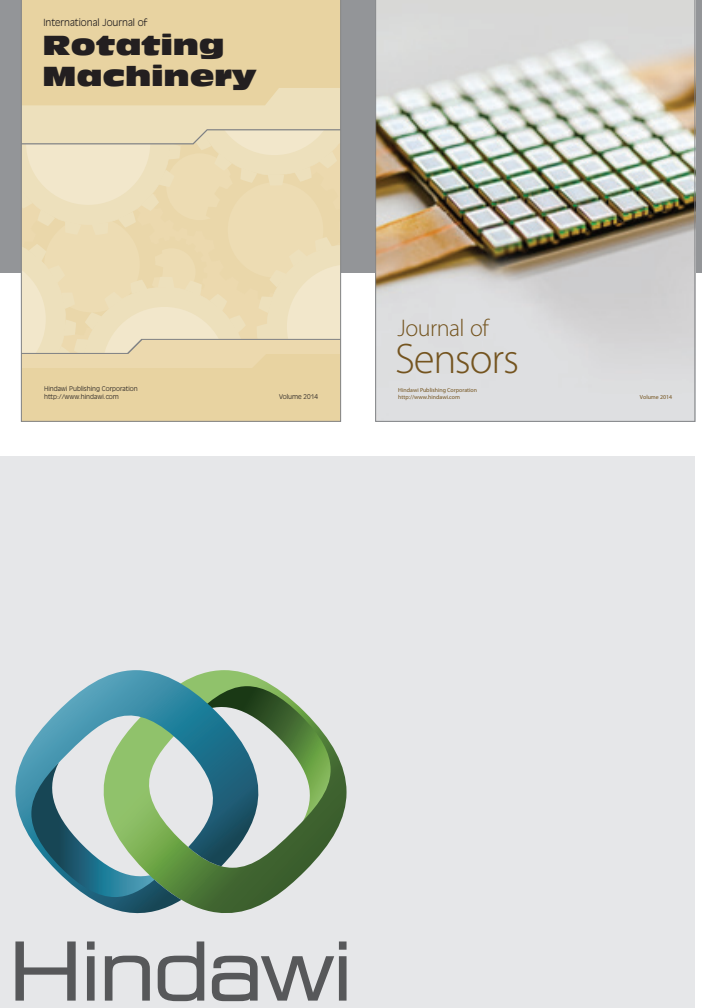

Submit your manuscripts at http://www.hindawi.com
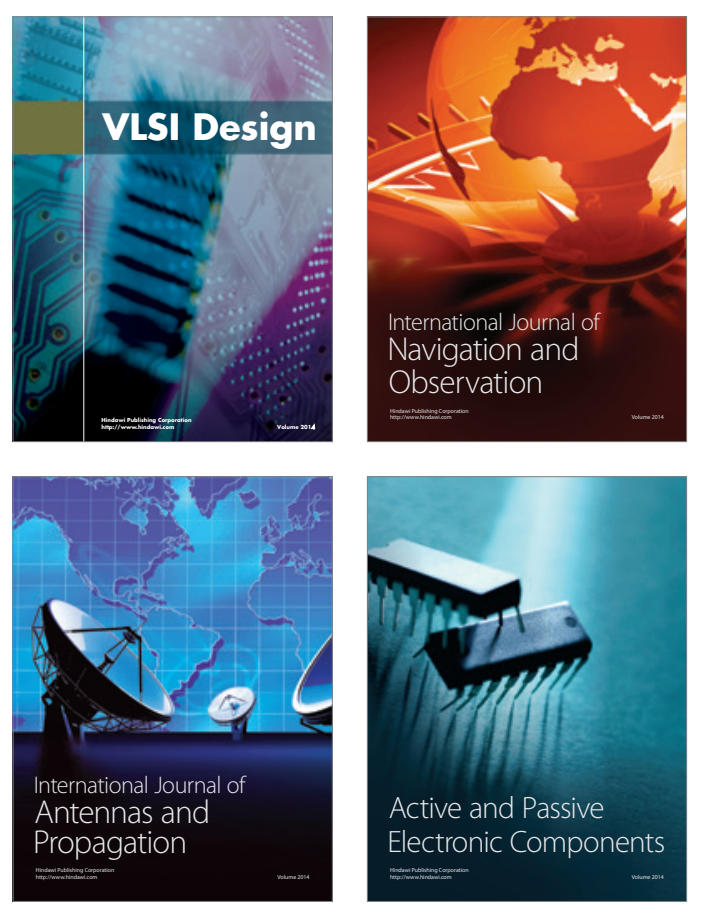
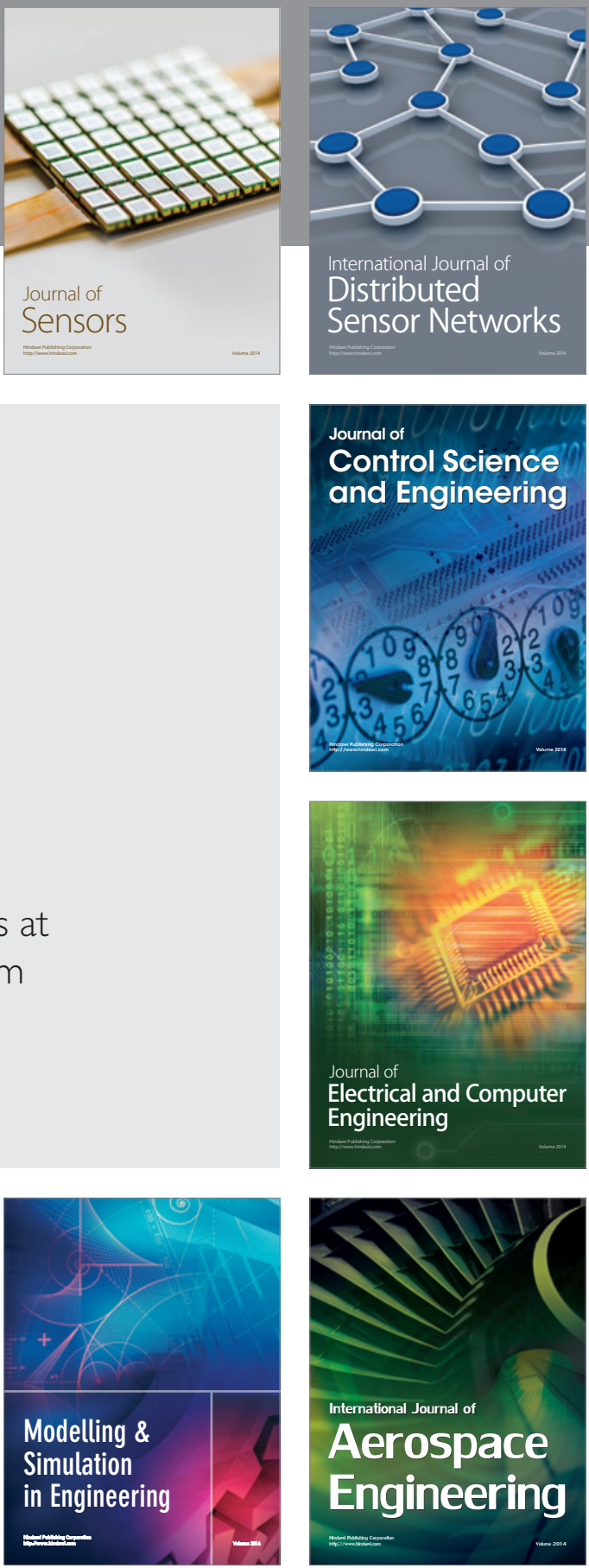

Journal of

Control Science

and Engineering
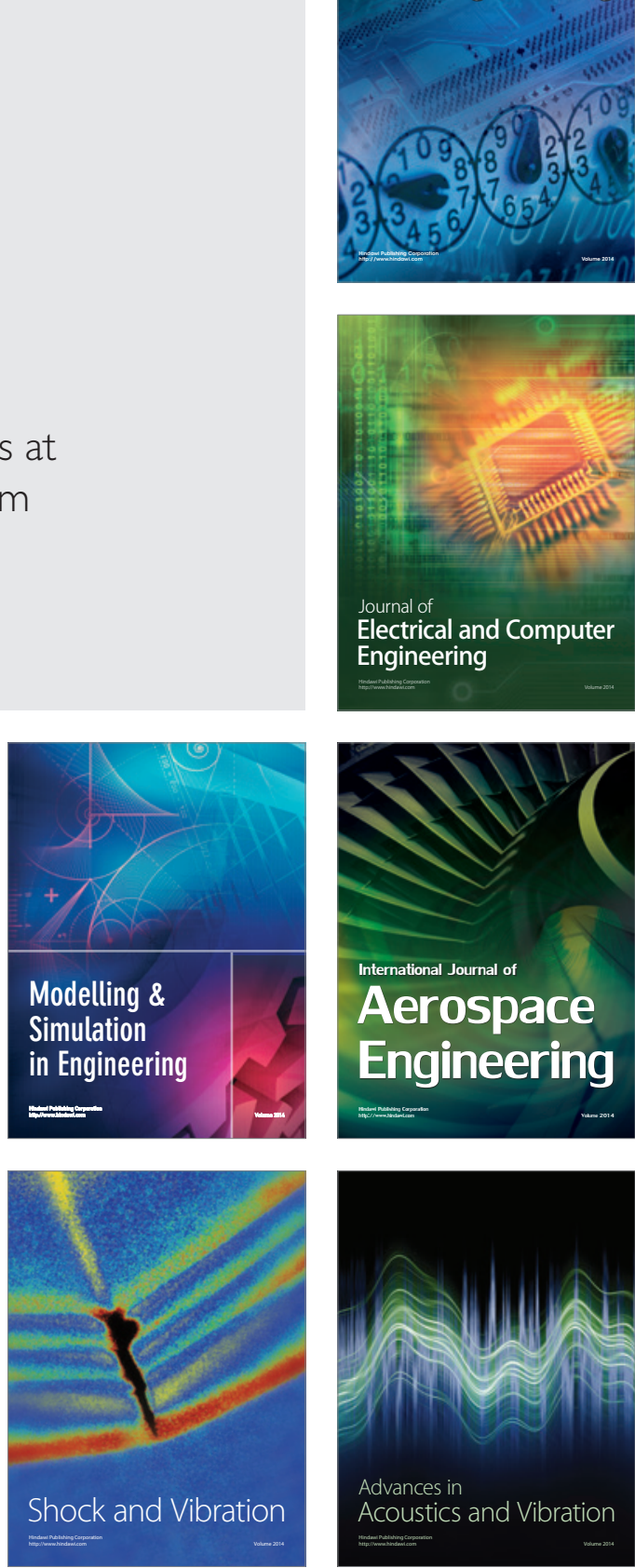